\title{
Viability of Bifidobacterium bifidum and Escherichia coli in Versus Prebiotic Effects of Jerusalem Artichoke (Helianthus tuberosus)
}

\author{
Elaheh Mansouri, ${ }^{1}$ Elnaz Milani,, ${ }^{2,}$ Ali Mohamadi Sani, ${ }^{1}$ and Ladan Nourbakhsh ${ }^{1}$ \\ ${ }^{1}$ Department of Food Science and Technology, Quchan Branch, Islamic Azad University, Quchan, Iran \\ ${ }^{2}$ Department of Food Processing, Iranian Academic Centre for Education Culture and Research, Mashhad, Iran \\ "Corresponding author: Elnaz Milani, Department of Food Processing, Iranian Academic Centre for Education Culture and Research, Mashhad, Iran. E-mail: \\ e_milani81@yahoo.com
}

Received 2015 August 05; Revised 2015 September 28; Accepted 2016 October 28.

\begin{abstract}
Background: In this study, in vitro prebiotic effects of Jerusalem artichoke poly-fructans on the survivability and activity of Bifidobacterium bifidum, Escherichia coli were investigated and compared with HP-Inulin (a high molecular-weight fraction of chicoryderived inulin).

Objectives: The prebiotic potential of poly-fructans extracted from native Jerusalem artichoke tubers on the survivability of $B$. $b i$ fidum and E. coli was evaluated in this study.

Methods: In this experimental study, 24 treatments divided to 2 groups (Extracted poly-fructose from Jerusalem artichoke tubers and standard inulin) randomly. The turbidity and $\mathrm{pH}$ variations during 48 hours incubation were determined using final concentrations of each group $(0.5 \%, 1 \%, 2 \%$ and $3 \%(\mathrm{w} / \mathrm{v}))$. The data were analyzed by MINITAB 14 and MSTATC statistical software, one way ANOVA and Duncan's test.

Results: This study suggests that Jerusalem artichoke tuber fructooligosaccharides (JA-Fr) had the potential to be used as a prebiotic component. The growth of B. bifidum improved significantly in the presence of Jerusalem artichoke fructans compared to the control. There was no significant differences $(\mathrm{P}<0.05)$ in Bifidobacterium population in different concentrations of Jerusalem artichoke polyfructans, but the population was significantly higher than the count in the presence of HP-inulin. The pH decreased in both media during 48 hours incubation time. Specific rate of growth and doubling time determined for $E$. coli demonstrated that the efficacy of various carbon sources in stimulating bacterial growth were influenced by the concentration and DP (degree of polymerization) of fructan chains in the media.

Conclusions: Jerusalem artichoke fructooligosaccharides can provide the greater stability of probiotics and acid production, so it can be considered as a potential source of high-yielding oligosaccharide for commercial prebiotic production to develop food industry and improve host health.
\end{abstract}

Keywords: Prebiotic, Jerusalem Artichoke, Inulin, Fructan

\section{Background}

Lactic acid bacteria is a major part of normal human and animal gut microflora. It is also important for maintaining gastrointestinal health. As a naturally occurring probiotic, Bifidobacteria and Lactobacilli can modify the metabolic activities in the body by modulating immune system [1], producing antimicrobial agents such as hydrogen peroxide, antimicrobial peptides (bacteriocins), and organic acids such as acetic and lactic acids [2]. When used in adequate amounts in diet, they can synthesis vitamins (such as $\mathrm{K}$ and B), stabilize barrier functions and enhance the calcium and other mineral absorption on the gut. Different studies have also demonstrated positive effects of probiotic bacteria on bowel $\mathrm{pH}$, intestinal regularity and the colonization resistance against pathogens $[3,4]$.
Prebiotics are Non-digestible food ingredients that allow beneficial changes. They may promote the survival or persistence of probiotic strains, enhance defense mechanisms of the host, increase resistance to various health disorders, and modify human gastrointestinal tract troubles [5]. Inulin type fructans fructooligosaccharides (FOS), and inulin are considered as prebiotics which are composed of $\beta$ (2-1) linked fructosy l units with or without a terminal Dglucose at the reducing end. They have different degree of polymerization (DP) and may originate naturally as native components in many plants or derive through biochemical/enzymatic techniques [6-8].

A number of in vitro and in vivo studies have confirmed that inulin kind fructans are fermented in to lactic and short-chain carboxylic acids. Functional activities of some 
commercial prebiotics like NutraFlora P-95 (DP = 2 - 4), Raftilose P95 (DP = 2 - 7), Inulin-S (DP = 2 - 60), Raftiline HP (DP > 23) and GOS (galactooligosaccharides) (DP = $2-4$ ) were assessed in in vitro studies [6]. Banuelos et al. tested the capacity of two probiotic strains, Lactobacillus gasseri CECT5714 and Lactobacillus fermentum CECT5716, to use several b (2-1) fructan mixtures as carbon source in in vitro cultures [8].

Jerusalem artichoke (Helianthus tuberosus) and Chicory (Cichorium intybus), belong to Compositae family, are two plant species used in commercial production of prebiotics $[9,10]$.

Jerusalem artichoke tuber contains nearly $13 \%$ - $18 \%$ carbohydrates, of which about $80 \%$ are inulin type fructans, $10 \%-13 \%$ sucrose, $3.5 \%-5 \%$ reducing sugars, $10 \%-17 \%$ proteins [11] and $0.8 \%-0.9 \%$ important minerals including $\mathrm{K}, \mathrm{Ca}, \mathrm{P}, \mathrm{Fe}, \mathrm{Zn}, \mathrm{Mg}, \mathrm{Na}, \mathrm{Cu}$ and $\mathrm{Mn}[12,13]$, and traditionally cultivates as food and animal feed [14].

In Jerusalem artichoke tubers the DP of fructans is rather low [15] and mainly depends on the plant source, variety, climate conditions and date of harvest $[16,17]$.

In the present study, the prebiotic potential of polyfructans extracted from native Jerusalem artichoke tubers on the survivability and activity of B. bifidum and E. coli was investigated in "in vitro" conditions, and compared with prebiotic effects of HP-inulin.

\section{Methods}

\subsection{Bacterial Strains}

Two strains of pure commercial cultures used were Bifidobacterium bifidumPTCC1644 and Escherichia coli PTCC 1330. Both of them obtained from Persian type culture collection.

\subsection{Media Preparation and Growth Conditions}

The standard prebiotic of HP-inulin purchased from Orafti (Tienen, Belgium).The fructooligosaccharides of Jerusalem artichoke tubers (JA-Fr) were extracted according to Milani et al. [18]. B. bifidum growth media were MRS broth (DeMan-Rogosa-Sharpe Broth) supplemented with L-cysteine hydrochloride $(0.5 \mathrm{~g} / \mathrm{L})$, sodium thioglycolate $(0.2 \mathrm{~g} / \mathrm{L})$, and $\mathrm{CaCl}_{2} .2 \mathrm{H}_{2} \mathrm{O}(0.1 \mathrm{~g} / \mathrm{L})$. TSB broth (Trypticase Soy Broth) was used for propagation of E. coli. Both media and all other chemicals purchased from Merck (Darmstadt, Germany). B. bifidum growth was anaerobically (Oxoid Anaerobic System with Gas Pak). The fructooligosaccharides free media were used as the control and the basal media which were sterilized by autoclaving at $121^{\circ} \mathrm{C}$ for
15 minutes. In the case of modified MRS broth, filtersterilized L-cysteine hydrochloride was added to the autoclaved media. The inoculums were prepared from the standard strains stored in glycerol $12 \%$ at $-70^{\circ} \mathrm{C}$ using basal media. The filter-sterilized carbohydrates (JA-Fr and HPinulin) added to the basal MRS broth and basal TSB broth to give final concentrations of $0.5 \%, 1 \%, 2 \%$ and $3 \%(w / v) .3 .3$ Growth measurement.

In order to investigate the effects of JA-Fr on the growth and survivability of Bifidobacterium bifidum and Escherichia coli strains, the bacteria were cultivated overnight in the appropriated basal medium at $37^{\circ} \mathrm{C}$. The activated cultures centrifuged for 15 minutes with $2500 \times$ g at $4^{\circ} \mathrm{C}$ (sigma centrifuge model 2 - $16 \mathrm{p}$ ), then the precipitate was washed twice with Phosphate-buffered saline (PBS) (0.1 M phosphate buffer $\mathrm{pH}=7.4,0.9 \%$ saline), and the final pellet was suspended in PBS and diluted to about $10^{6}$ cells/mL for B. bifidum and $10^{9}-10^{10}$ cells/mL for E. coli. The bacterial suspensions were inoculated at $1 \%(\mathrm{v} / \mathrm{v})$ concentration in to different testing media containing fructans. Then the cultures were incubated at $37^{\circ} \mathrm{C}$ for 24 hours. The turbidity at 620 nm of each culture was determined every 4 hours by subtracting A_620values of bacterial free medium from each test media. All measurements were repeated at least twice.

\subsection{Growth Kinetic Parameters}

Specific growth rate $(\mu)$ was calculated for each microorganism during its exponential growth phase by the formula:

Equation 1.

$\mu=\frac{\operatorname{Ln} x-\operatorname{Ln} X_{0}}{t-t_{0}}$

Where $\mathrm{x}$ and $\mathrm{x}_{0}$ are absorbance measured at time $\mathrm{t}$ and $t_{0}$, respectively.

The generation time $(\mathrm{tg})$ was calculated for each culture from the corresponding value of $(\mu)$ by the formula:

$\operatorname{tg}=\frac{\operatorname{Ln} 2}{\mu}$

\section{4. $p H$ Changes}

$\mathrm{pH}$ value was measured using Inolab $\mathrm{pH}$ meter model WTW (Inolab).

\subsection{Statistical Analysis}

The obtained results were analyzed by MINITAB 14 and MSTATC software and significant differences between groups were determined by the Duncan's multiple range test. Differences were considered significant at $\mathrm{P}<0.05$. 


\section{Results}

\subsection{Effects of Fructans on Microbial Populations}

Bifidobacterium bifidum and Escherichia coli are the strains associated with human and animal digestive systems. In vitro experiments on the comparative fermentation of selected fructooligosaccharides showed that the $J A$ Fr was fermented by B. bifidumPTCC1644, and it had the potential to stimulate the growth of bacteria (Table 1).

As shown in Table 2, supplementation with JA-Fr was found to have significantly better effect on survivability of the bacteria compared with that without JA-Fr $(\mathrm{P}<0.05)$. We did not observed significant differences in the amount of cell growth as the concentration of $J A-F r$ rose to $3 \%(w / v)$. Growth curve of B. bifidum showed that the bacteria grew rapidly after about 8 hours, with maximum growth observed at about 24 hours (Figure 1). Determined turbidities of the media containing JA-Fr were significantly $(\mathrm{P}<0.05)$ higher than the ones containing HP-inulin, indicating that $J A-F r$ was more effective in modifying the growth behavior of Bifidobacterium bifidum PTCC1644.

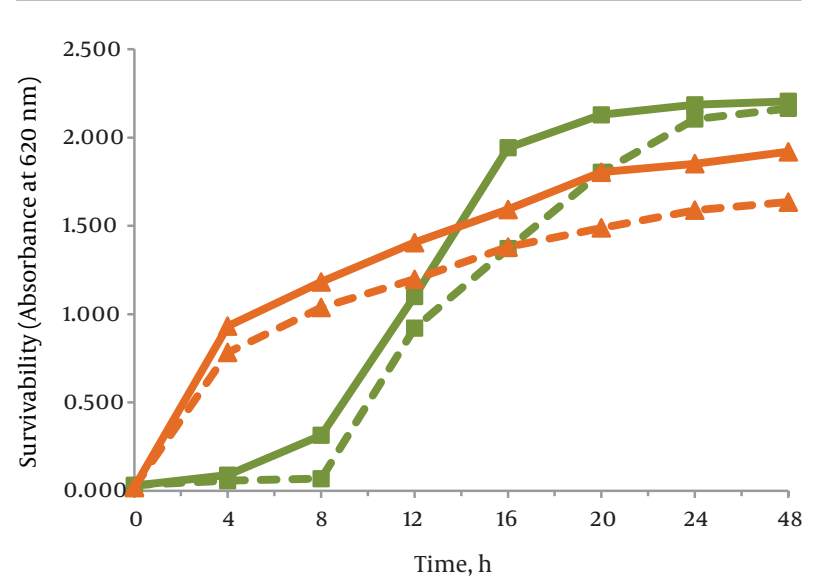

Figure 1. Growth kinetics of B. bifidum ( $\mathbf{\square})$ and E. coli $(\mathbf{\Lambda})$ in appropriate medium enriched with JA-Fr (Rectangle) and HP-inulin (...) at $2 \%$ (w/v) during 48-hour incubation at $37^{\circ} \mathrm{C}$

Specific rates of growth were determined for the media supplemented with $2 \%$ (w/v) JA-Fr compared to the control and HP-inulin (Table 3). JA-Fr caused greater in vitro growth rate of Bifidobacterium than did the control and HP-inulin.

To study the effects of different fructans on the growth of $E$. coli, the organism were cultured in the appropriate media supplemented with different concentrations of fructooligosaccharides at $37^{\circ} \mathrm{C}$. Results showed that they were fermented by the microbial flora (Table 4). Growth promotion of E. coli by JA-Fr has been dose dependent over the range $0.5 \%$ to $3 \%$ as evidenced by increased turbidity of the bacteria suspensions (Table 5), indicating that E. coli grew faster in the presence of these carbohydrates. Figure 2 shows the growth curves of $E$. coli strain cultured with both carbon sources. HP-inulin was found to be less effective on the viability of $E$. coli.

The doubling time $(\mathrm{tg})$ of the strain grown in the presence of $J A-F r$, HP-inulin and the control medium are compared in Table 3. Doubling time was used as a measure of the efficacy of various carbon sources in modulating growth rate. According to Table $3, \mathrm{tg}$ in the medium containing $J A-F r$ was minimal.

\section{2. pH Evaluation}

The $\mathrm{pH}$ was recorded for the cultures with various carbohydrates. In accordance with growth stimulation, acid production by Bifidobacterium was also enhanced $(\mathrm{P}<$ 0.05 ) by the presence of JA-Fr in the media compared to the control (Table 6).

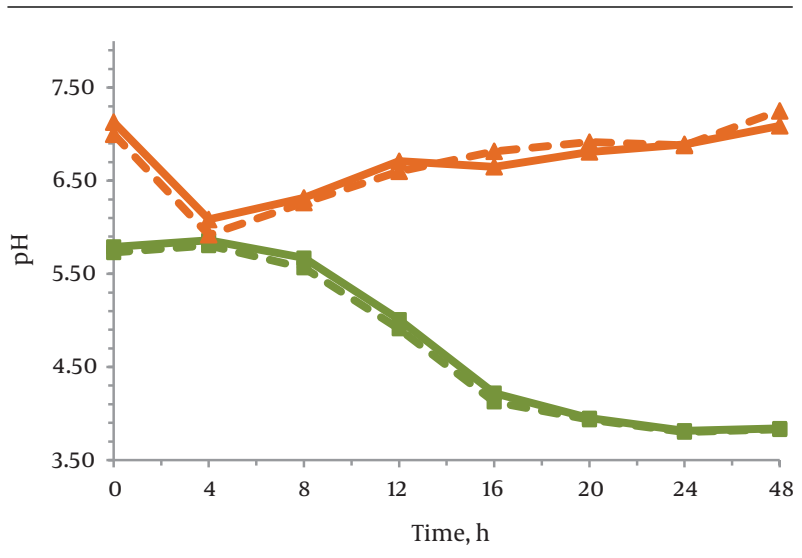

Figure 2. Changes in $\mathrm{pH}$ of media inoculated with B. bifidum ( $\mathbf{\square})$ and E. coli $(\mathbf{\Lambda})$ in appropriate medium enriched with JA-Fr (Rectangle) and HP-inulin (...) at $2 \%$ (w/v) during 48 -h incubation at $37^{\circ} \mathrm{C}$

As shown in Figure 2, the $\mathrm{pH}$ continued to decline in a similar way in the presence of both $J A-F r$ and HP-inulin. After 24 hours of incubation, the pH dropped to 3.76 in JA-Frcontaining media, and to 3.87 in media with HP-inulin. The difference of $\mathrm{pH}$ values between two fructans was not significant $(\mathrm{P}<0.05)$. Table 7 demonstrates the changes in TSB medium $\mathrm{pH}$ with different concentrations of $J A-F r$ which occur during fermentation.

$\mathrm{pH}$ has similar behavior in both media containing JAFr and HP-inulin. It was approximately 7.0 prior to inoculation, then there was a continued fall in medium $\mathrm{pH}$ over the first 4 hours and at this time, it began to rise (Figure 2). The difference between the $\mathrm{pH}$ values of two media was significant $(\mathrm{P}<0.05)$. 
Table 1. Comparative Growth of B. bifidum in the Presence of $J A-F r$, HP-Inulin and in Control Medium

\begin{tabular}{lcr}
\hline & & Bifidobacterium bifidum \\
\hline Fructan in the growth media & Control & JA-Fr \\
Absorbance at $620 \mathrm{~nm}$ & $1.198 \pm 0.06^{\mathrm{b}}$ & $1.237 \pm 0.06^{\mathrm{a}}$ \\
P-Value & 0.004 & 0.004 \\
\hline
\end{tabular}

${ }^{\mathrm{a}}$ The data represent the results of a duplicate experiment.

Table 2. Effects of $J A-F r$ Concentrations on the Viability of B. bifidum ${ }^{\mathrm{a}}$

\begin{tabular}{lcccc}
\hline & & & Bifidobacterium bifidum \\
\hline JA-Fr Concentration (w/v) & $0 \%$ & $0.5 \%$ & $1 \%$ & $2 \%$ \\
Survivability (Absorbance at 620nm) & $1.090 \pm 0.003^{\mathrm{b}}$ & $1.239 \pm 0.008^{\mathrm{a}}$ & $1.217 \pm 0.004^{\mathrm{a}}$ & $1.266 \pm 0.009^{\mathrm{a}}$ \\
P-Value & 0.002 & 0.009 & 0.005 & 0.001 \\
\hline
\end{tabular}

${ }^{\mathrm{a}}$ Different letters mean statistically significant difference among the values of the same parameter, according to Duncan test $(\mathrm{P}<0.05)$.

Table 3. Comparison of Bacterial Specific Growth rates $(\mu)$ and Doubling Times $(\operatorname{tg})$ in the Presence of Different Fructans ${ }^{\mathrm{a}, \mathrm{b}}$

\begin{tabular}{|c|c|c|}
\hline & Bifidobacterium bifidum & Escherichia coli \\
\hline \multicolumn{3}{|l|}{ Control } \\
\hline$\mu$ & $0.126 \pm 0.007$ & $0.902 \pm 0.003$ \\
\hline $\operatorname{tg}$ & $5.50 \pm 0.007$ & $0.76 \pm 0.003$ \\
\hline \multicolumn{3}{|l|}{ JA-Fr } \\
\hline$\mu$ & $0.142 \pm 0.006^{*}$ & $0.973 \pm 0.004^{*}$ \\
\hline $\operatorname{tg}$ & $4.88 \pm 0.006^{*}$ & $0.71 \pm 0.004^{*}$ \\
\hline \multicolumn{3}{|l|}{ HP-inulin } \\
\hline$\mu$ & $0.099 \pm 0.001$ & $0.905 \pm 0.007$ \\
\hline $\operatorname{tg}$ & $6.97 \pm 0.001$ & $0.77 \pm 0.007$ \\
\hline
\end{tabular}

${ }^{\mathrm{a}}$ All values for $\mu\left(\mathrm{h}^{-1}\right)$ and $\operatorname{tg}(\mathrm{h})$ are means from duplicate determination $\pm \mathrm{SD}$.

${ }^{\mathrm{b}}$ Significant differences at $\mathrm{P}<0.05$ confidence intervals (according to Duncan test) are shown as *

Table 4. Comparative growth of $E$. coli in the presence of $J A-F r$, HP-inulin and in control medium ${ }^{\mathrm{a}}$

\begin{tabular}{lcc}
\hline & & Escherichia coli \\
\hline Fructan in the growth media & Control & JA-Fr \\
Absorbance at $620 \mathrm{~nm}$ & $1.192 \pm 0.08^{\mathrm{b}}$ & $1.233 \pm 0.05^{\mathrm{a}}$ \\
P-Value & 0.006 & 0.001 \\
\hline
\end{tabular}

${ }^{\mathrm{a}}$ The data represent the results of a duplicate experiment.

\section{Discussion}

Our experiments on the supplementation with $J A-F r$ and HP-inulin showed that the JA-Fr had better effect on survivability of B. bifidumPTCC1644. Specific rate of growth determined for E. coli revealed that the efficacy of various carbon sources in stimulating bacterial growth were influ- enced by the concentration and DP of fructan chains in the media.

The ability of Bifidobacteria to utilize fructooligosaccharides has been reviewed in many studies and the lowering of culture $\mathrm{pH}$ as a result of short chain fatty acids production for certain bacterial species has often been used as 
Table 5. Effects of $J A-F r$ concentrations on the viability of $E$. coli ${ }^{\text {a }}$

\begin{tabular}{lccccc}
\hline & & & \multicolumn{2}{c}{ Escherichia coli } \\
\hline JA-Fr Concentration (w/v) & $0 \%$ & $0.5 \%$ & $1 \%$ & $2 \%$ \\
Survivability (Absorbance at $620 \mathbf{~ n m})$ & $1.192 \pm 0.002^{\mathrm{e}}$ & $1.272 \pm 0.005^{\mathrm{d}}$ & $1.347 \pm 0.007^{\mathrm{b}}$ & $1.392 \pm 0.002^{\mathrm{a}}$ & $1.318 \pm 0.009^{\mathrm{c}}$ \\
P-Value & 0.002 & 0.004 & 0.001 & 0.004 \\
\hline
\end{tabular}

${ }^{\text {a }}$ Different letters mean statistically significant difference among the values of the same parameter, according to Duncan test $(\mathrm{P}<0.05)$.

Table 6. Effects of JA-Fr Concentrations on pH Changes of Media Inoculated with B. bifidum

\begin{tabular}{lccccc}
\hline & & \multicolumn{3}{c}{ Bifidobacterium bifidum } \\
\hline JA-Fr Concentration $(\mathbf{w} / \mathbf{v})$ & $0 \%$ & $0.5 \%$ & $1 \%$ & $2 \%$ & $4.80 \pm 0.006^{\mathrm{c}}$ \\
pH & $4.86 \pm 0.009^{\mathrm{a}}$ & $4.84 \pm 0.005^{\mathrm{a}, \mathrm{b}}$ & $4.82 \pm 0.008^{\mathrm{b}, \mathrm{c}}$ & $4.75 \pm 0.006^{\mathrm{d}}$ \\
P-Value & 0.003 & 0.001 & 0.003 & 0.002 \\
\hline
\end{tabular}

${ }^{\mathrm{a}}$ Different letters mean statistically significant difference among the values of the same parameter, according to Duncan test $(\mathrm{P}<0.05)$.

Table 7. Effects of $J A-F r$ concentrations on $\mathrm{pH}$ changes of media inoculated with E. coli $^{\text {a }}$

\begin{tabular}{lccccc}
\hline & & \multicolumn{3}{c}{ Escherichia coli } \\
\hline JA-Fr Concentration $(\mathbf{w} / \mathbf{v})$ & $0 \%$ & $0.5 \%$ & $1 \%$ & $2 \%$ & $6.79 \pm 0.008 \mathrm{~b}$ \\
pH & $6.78 \pm 0.005^{\mathrm{b}}$ & $6.72 \pm 0.009^{\mathrm{c}}$ & $6.86 \pm 0.004^{\mathrm{a}}$ & $6.50 \pm 0.003^{\mathrm{d}}$ \\
P-Value & 0.003 & 0.005 & 0.003 & 0.003 \\
\hline
\end{tabular}

${ }^{\mathrm{a}}$ Different letters mean statistically significant difference among the values of the same parameter, according to Duncan test $(\mathrm{P}<0.05)$.

an index of the fermentability of various carbohydrates in the culture [19]. Our results demonstrated that the viability of Bifidobacterium bifidumPTCC1644 and Escherichia coliPTCC 1330 in the media depend on the type and concentration of carbon source. Jerusalem artichoke fructooligosaccharides can be considered as a potential source for prebiotic production because it can provide the greater stability of probiotics and acid production.

Biedrzycka and Bielecka reported that the in vitro consumption of inulin by Bifidobacteria depended to purity and degree of polymerization of fructo-oligomeric chains. Their research indicated that the majority of Bifidobacterium strains studied utilized short chain FOS and OF [20]. Watson et al. showed that Lactulose, maltodextrin, FOS, GOS and the GOS/inulin (9: 1) mixture stimulate the growth performance of Bifidobacteria (12 different species), while inulin and polydextrose appeared to be rather poor substrates for bifidobacterial growth [21]. Inconsistent findings, Vigsnas et al. demonstrated that $B$. adolescentis and $B$. longum are able to degrade linear arabino-oligosaccharides (DP 8 ), whereas $B$. breve is able only to hydrolyze FOS and B. bifidum is not able to degrade either FOS or AOS [22].
Wichienchot et al. used mixed oligosaccharides obtained from white-flesh dragon fruit (Pitaya) and a reference prebiotic (inulin) as carbon sources for the cultivation of B. bifidum NCIMB 702715. It was found that inulin had a greater effect on the bacterial growth compared to Pitaya oligosaccharides, although the difference was not significant [23]. In another study, Wang et al. showed that the numbers of Bifidobacterium bifidumATCC 29521 were greater than those in control medium $(\mathrm{P}<$ 0.05 ) when cultured in the medium supplemented with alginate oligosaccharides. This compound stimulated the growth of B. bifidum, more significantly in comparison with fructo-oligosaccharides (FOS) [24].

In general, the ability of coliforms to utilize prebiotic oligosaccharides has been contradictory. Several studies have reported that FOS can support growth of E. coli, Enterobacter and Salmonella $[25,26]$. In contrast, others have indicated that E. coli is unable to utilize FOS [27]. LopezMolina et al. studied the utilization of chicory and Artichoke inulin (different DP) in mixed cultures of colonic bacteria and showed that growth of Escherichia coli and total anaerobes was slower but longer-lasting in the presence of both inulins compared to the control with glucose [28]. 
Van Laere et al. reported that arabino-oligosaccharides could support the growth of E. coli but FOS could not [29].

Our findings were implying that the degree of polymerization of fructans was an important factor that decides the accessibility of fructans to the bacteria. According to Biedrzycka and Bielecka, susceptibility of saccharides to fermentation mainly depends on water solubility, chemical structure and degree of polymerization, chain length, branched or linear structure and composition of monomer units [19]. Shetty et al. reported that in "in vitro" fermentation of inulin by human fecal bacteria, molecules with DP $>10$ were fermented on the average half as quickly as molecules with $\mathrm{DP}<10$ [30]. The degree of polymerization of fructans from Helianthus tuberosus tubers is rather low [15] in comparison with HP-inulin and mainly depends on the variety, climate conditions and time of harvest [16, 17]. In body, the lower $\mathrm{pH}$ is believed to have additional effects because the production of these acids reduces intestinal $\mathrm{pH}$ and restricts or prohibits the growth of many pathogen and putrefactive bacteria. Also it increases mineral uptake [31]. In the case of Escherichia coli, casein is a principal nutrient in TSB medium; so the changes in $\mathrm{pH}$ curves are probably due to cells metabolism especially the deamination of amino acids during bacterial growth [19, 32].

\subsection{Conclusions}

Regarding to the concept of synbiotic which is a mixture of probiotics and prebiotics that synergistically enhance equilibrium of the gastrointestinal microflora, finding new natural resources containing various prebiotic components could be an appropriate way to develop food industry and improve host health. Our results revealed that the survival and metabolic activity of Bifidobacterium bifidum PTCC1644 and Escherichia coli PTCC 1330 in the media depend on the type and concentration of carbon source. Jerusalem artichoke fructooligosaccharides can provide the greater stability of probiotics and acid production, so it can be considered as a potential source of highyielding oligosaccharide for commercial prebiotic production; however further investigations are needed with other probiotic strains and in in vivo conditions to optimize the fructans concentration and bacterial growth.

\section{Acknowledgments}

This research was supported by the Iranian academic centre for education culture and research (ACECR) under the project 2353, which provided facilities for this work.

\section{Footnotes}

Authors' Contribution: Elnaz Milani designed, performed experiments, analyzed data and wrote the paper; Elaheh Mansouri designed, performed experiments and wrote the paper; Ali Mohamadi Sani and Ladan Nourbakhsh developed analytical tools.

Conflict of Interest: The authors declare that there is no conflict of interest to disclose.

Funding/Support: Department of food science and technology, Quchan branch, Islamic Azad University, Quchan, Iran.

\section{References}

1. Ibrahim F, Ruvio S, Granlund L, Salminen S, Viitanen M, Ouwehand AC. Probiotics and immunosenescence: cheese as a carrier. FEMS Immunol Med Microbiol. 2010;59(1):53-9. doi: 10.1111/j.1574-695X.2010.00658.x. [PubMed: 20236323].

2. Anderson RA, Aroutcheva A, Feathergill KA, Anderson AB. Differential Sensitivity of Lactobacillus spp. to Inhibition by Candidate Topical Microbicides. Probiotics Antimicrob Proteins. 2009;1(1):24-35. doi: 10.1007/s12602-009-9007-x. [PubMed: 26783129].

3. Iannitti $\mathrm{T}$, Palmieri B. Therapeutical use of probiotic formulations in clinical practice. Clin Nutr. 2010;29(6):701-25. doi: 10.1016/j.clnu.2010.05.004. [PubMed: 20576332].

4. Mikov MM, Stojančević MP, Bojić GM. Probiotics as a promising treatment for inflammatory bowel disease. Hospital Pharmacol. 2014;1:5260.

5. Mountzouris KC, Balaskas C, Fava F, Tuohy KM, Gibson GR, Fegeros K. Profiling of composition and metabolic activities of the colonic microflora of growing pigs fed diets supplemented with prebiotic oligosaccharides. Anaerobe. 2006;12(4):178-85. doi: 10.1016/j.anaerobe.2006.04.001. [PubMed: 16731014].

6. Singh RS, Singh RP. Production of fructooligosaccharides from inulin by endoinulinases and their prebiotic potential. Food Technol Biotechnol. 2010;48(4):435.

7. Nakakuki T. Present status and future of functional oligosaccharide development in Japan. Pure App Chem. 2002;74(7):1245-51. doi: 10.1351/pac200274071245.

8. Banuelos O, Fernandez L, Corral JM, Valdivieso-Ugarte M, Adrio JL, Velasco J. Metabolism of prebiotic products containing beta(2-1) fructan mixtures by two Lactobacillus strains. Anaerobe. 2008;14(3):184-9. doi: 10.1016/j.anaerobe.2008.02.002. [PubMed: 18434219].

9. Kaur N, Gupta AK. Applications of inulin and oligofructose in health and nutrition. J Biosci. 2002;27(7):703-14. [PubMed:12571376].

10. Leroy G, Grongnet JF, Mabeau S, Corre DL, Baty-Julien C. Changes in inulin and soluble sugar concentration in artichokes (Cynara scolymus L.) during storage. J Sci Food Agric. 2010;90(7):1203-9. doi: 10.1002/jsfa.3948. [PubMed: 20394002].

11. Patkai GY, Barta J, editors. Nutritive value of different Jerusalem artichoke varieties. 9th Seminar on Inulin. 2002; p. 19.

12. Nemeth G, Izsáki Z. Macro-and micro-element content and uptake of Jerusalem artichoke (Helianthus tuberosus L). Cereal Res Communicat. 2006;34(1):597-600.

13. Barta J, Patkai GY. Chemical composition and storability of Jerusalem artichoke tubers. Acta Alimentaria. 2007;36(2):257-67. doi: 10.1556/AAlim.36.2007.2.13.

14. Baldini M, Danuso F, Turi M, Vannozzi G. Evaluation of new clones of Jerusalem artichoke (Helianthus tuberosus L.) for inulin and sugar yield from stalks and tubers. Indust Crops Product. 2004;19(1):25-40. doi: 10.1016/S0926-6690(03)00078-5. 
15. Bohm A, Kaiser I, Trebstein A, Henle T. Heat-induced degradation of inulin. Europ Food Res Technol. 2005;220(5-6):466-71. doi: 10.1007/s00217-004-1098-8.

16. Bekers M, Grube M, Upite D, Kaminska E, Linde R, Scherbaka R, et al. Carbohydrates in Jerusalem artichoke powder suspension. Nutrition Food Sci. 2007;37(1):42-9. doi:10.1108/00346650710726940.

17. Paseephol T, Small D, Sherkat F. Process optimisation for fractionating Jerusalem artichoke fructans with ethanol using response surface methodology. Food Chem. 2007;104(1):73-80.

18. Milani E, Koocheki A, Golimovahhed Q. Extraction of inulin from Burdock root (Arctium lappa) using high intensity ultrasound. Int J Food Sci Technol. 2011;46(8):1699-704. doi: 10.1111/j.1365-2621.2011.02673.x.

19. Winarti S, Harmayani E, Marsono Y, Pranoto Y. Effect of inulin isolated from lesser yam (Dioscorea esculenta) on the growth of probiotics bacteria and SCFA formation during fermentation. Int Res J Microbiol. 2013;4(2):53-63.

20. Biedrzycka E, Bielecka M. Prebiotic effectiveness of fructans of different degrees of polymerization. Trends Food Sci Technol. 2004;15(3):1705. doi: 10.1016/j.tifs.2003.09.014.

21. Watson D, O'Connell Motherway M, Schoterman MH, van Neerven RJ, Nauta A, van Sinderen D. Selective carbohydrate utilization by lactobacilli and bifidobacteria. J Appl Microbiol. 2013;114(4):1132-46. doi: 10.1111/jam.12105. [PubMed: 23240984].

22. Vigsnaes LK, Holck J, Meyer AS, Licht TR. In vitro fermentation of sugar beet arabino-oligosaccharides by fecal microbiota obtained from patients with ulcerative colitis to selectively stimulate the growth of Bifidobacterium spp. and Lactobacillus spp. Appl Environ Microbiol. 2011;77(23):8336-44. doi: 10.1128/AEM.05895-11. [PubMed: 21984234].

23. Wichienchot $S$, Jatupornpipat M, Rastall RA. Oligosaccharides of pitaya (dragon fruit) flesh and their prebiotic properties. Food Chem. 2010;120(3):850-7.

24. Wang Y, Han F, Hu B, Li J, Yu W. In vivo prebiotic properties of alginate oligosaccharides prepared through enzymatic hydrolysis of alginate. Nutrition Res. 2006;26(11):597-603.

25. Roberfroid M. Inulin-type fructans: functional food ingredients. CRC Press; 2004.

26. Vijayakumari SJ, Sasidharannair NK, Nambisan B, Mohandas C. Optimization of media and temperature for enhanced antimicrobial production by bacteria associated with Rhabditis sp. Iran J Microbiol. 2013;5(2):136-41. [PubMed: 23825731].

27. Holt SM, Miller-Fosmore CM, Cote GL. Growth of various intestinal bacteria on alternansucrase-derived oligosaccharides. Lett Appl Microbiol. 2005;40(5):385-90. doi: 10.1111/j.1472-765X.2005.01681.X. [PubMed: 15836744].

28. Lopez-Molina D, Navarro-Martinez MD, Rojas Melgarejo $\mathrm{F}$, Hiner AN, Chazarra S, Rodriguez-Lopez JN. Molecular properties and prebiotic effect of inulin obtained from artichoke (Cynara scolymus L.). Phytochemistry. 2005;66(12):1476-84. doi: 10.1016/j.phytochem.2005.04.003. [PubMed: 15960982].

29. Van Laere KM, Hartemink R, Bosveld M, Schols HA, Voragen AG. Fermentation of plant cell wall derived polysaccharides and their corresponding oligosaccharides by intestinal bacteria. J Agric Food Chem. 2000;48(5):1644-52. [PubMed: 10820072].

30. Shetty K, Paliyath G, Pometto A, Levin RE, Casci T, Gibson GR, et al. Food Biotechnology, Second Edition. CRC Press; 2005. Human gut microflora in health and disease.

31. Baffoni L, Gaggìa F, Di Gioia D, Biavati B. Role of intestinal microbiota in colon cancer prevention. Annals Microbiol. 2012;62(1):15-30. doi: 10.1007/s13213-011-0306-6.

32. Hedderich R, Klees A, Eiermann K, Greulich Y, Müller R, editors. Growth promoting properties of a vegetable peptone broth (VPB) in comparison to tryptic soy broth (TSB). Poster presented at the pda's 4 th annual global conference on pharmaceutical microbiology. 2009; . 